\title{
EDUCAÇÃO PARA A SUSTENTABILIDADE E CIDADANIA GLOBAL: UM ESTUDO NA PERSPECTIVA DAS ORIENTAÇÕES DA UNESCO ${ }^{1}$
}

\author{
EDUCATION FOR SUSTAINABILITY AND GLOBAL CITIZENSHIP: \\ A STUDY FROM THE PERSPECTIVE OF UNESCO GUIDELINES
}

\author{
Antonio Paulo Valim Vega ${ }^{2}$ e Noemi Boer ${ }^{3}$
}

\section{RESUMO}

Neste artigo tem-se como objetivo resgatar na história da Educação Ambiental (EA) e nos documentos da UNESCO as questões relativas à educação para a sustentabilidade e para a cidadania global, buscando contribuir com os processos da educação formal e não formal. Considerando a proposta da Educação para o Desenvolvimento Sustentável (EDS) e sua associação com a Educação para a Cidadania Global (ECG), pretende-se identificar algumas possibilidades de educação para a cidadania, compreender a relação entre educação e a necessidade socioambiental, e, contextualizar a construção de competências e habilidades pessoais e coletivas, que enseja, a sustentabilidade solidária. O estudo apresenta abordagem qualitativa descritiva e caracteriza-se como revisão bibliográfica.

Palavras-chave: Ensino, Aprendizagem, Meio-ambiente, Cidadania, Competências

\section{ABSTRACT}

This article aims to rescue issues related to education for sustainability and global citizenship in the history of Environmental Education (EA) and in UNESCO's documents, seeking to contribute to the processes of formal and non-formal education. Considering the proposal for Education for Sustainable Development (EDS) and its association with Education for Global Citizenship (ECG), it is intended to identify some possibilities of education for citizenship, to understand the relationship between education and socio-environmental needs, and contextualize the construction of personal and collective skills and abilities, which leads to solidarity sustainability. The study presents a qualitative and descriptive approach and is characterized as a bibliographic review.

Keywords: Teaching, Learning, Environment, Citizenship, Skills.

\footnotetext{
${ }^{1}$ Artigo relacionado à dissertação, elaborada pelo primeiro autor.

${ }^{2}$ Acadêmico do Curso de Mestrado Acadêmico em Humanidades e Linguagens - MEHL - Universidade Franciscana UFN. E-mail: paulovega1010@gmail.com

${ }^{3}$ Orientadora. Universidade Franciscana - UFN. E-mail: noemiboer@gmail.com.br
} 


\section{INTRODUÇÃO}

A educação é uma prioridade e um direito humano básico. Acredita-se que ela contém os pressupostos necessários para ajudar na construção da uma sociedade pacífica, solidaria e sustentável da forma como preconizam vários instrumentos legais e éticos.

Desde a década de 1990, o discurso do desenvolvimento sustentável, doravante DS, vem adquirindo expressão e relevância nos debates relativos ao desenvolvimento e meio ambiente. De acordo com Lima (2009), o DS diz respeito a uma multiplicidade de entendimentos nas dimensões sociais e culturais. No campo educacional aparece com destaque a proposta de Educação para o Desenvolvimento Sustentável (EDS) ou a Educação para a Sustentabilidade.

Tais propostas são defendidas e apresentadas principalmente por um conjunto de organizações e instituições como a Organização das Nações Unidas (ONU), a Organização das Nações Unidas para Educação, Ciência e Cultura (UNESCO), que influenciam as políticas públicas nacionais e internacionais. Nessa perspectiva, a Unesco vem promovendo a EDS desde 1992 e reconheceu o período, 2005-2014, como a Década da Educação para o Desenvolvimento Sustentável. Atualmente, está à frente do Programa da Ação Global (Global Action Programme, GAP), igualmente voltado à EDS (UNESCO, 2017).

A organização das Nações Unidas entra no terceiro milênio, com a proposta de uma ação global, para tanto, reuniu líderes mundiais para definir e comunicar ao mundo uma visão ampla, capaz de expressar o desejo e a necessidade de combater a pobreza nas suas várias dimensões. Essa visão, foi traduzida em oito Objetivos de Desenvolvimento do Milênio (ODM), os quais, durante 15 anos foram o eixo orientador da linha de desenvolvimento para o mundo.

A UNESCO, é responsável por liderar e coordenar a Agenda da Educação 2030, um plano de ação para as pessoas, para o planeta e para a prosperidade, parte de um movimento global para erradicar a pobreza, e está apoiada, nos 17 Objetivos dos Desenvolvimento Sustentável (ODS). A educação é um dos pontos essenciais para ajudar a atingir esses objetivos. O objetivo número quatro (4) diz o seguinte: "Assegurar a educação inclusiva e equitativa de qualidade e promover oportunidades de aprendizagem ao longo da vida para todos" (UNESCO, 2017, p. 18). Porém, também nos outros ODS, a educação está contemplada em termos de metas e indicadores.

A necessidade de uma EDS, nunca foi tão premente quanto nesses tempos atuais, em que o crescimento econômico e a criação de riquezas reduziram as taxas globais de pobreza, mas a desigualdade, a exclusão e a violência aumentaram dentro das sociedades e entre diferentes sociedades em todo o mundo (UNESCO, 2016a). A degradação ambiental, mudança climática, poluição, consumo exacerbado, resíduos aparecem em padrões insustentáveis e não param de aumentar.

Os impactos desses fenômenos são evidentes e pedem por transformação e mudanças no estilo de vida, na forma de pensar e agir. Por conta disso, a humanidade precisa aprender e significar 
novos valores, habilidades e atitudes que possam conduzir as sociedades humanas à hábitos de vida mais sustentáveis.

Compartilhando um projeto de educação com a EDS, a UNESCO trabalha também com a abordagem da Educação para a Cidadania Global (ECG). A cidadania global ganhou expressão em associação à esfera do desenvolvimento com o lançamento da Iniciativa Global Educação em Primeiro Lugar (GEFI), em 2012, identificou o fomento a cidadania global como uma das três áreas prioritárias de trabalho, juntamente com o acesso e a qualidade da educação.

Essa reflexão se apoia e dialoga com algumas referências históricas do DS, compreende um campo amplo de pensamento sobre meio ambiente, complexidade, e globalização, EDS, ECG temas que se situam entre as questões da educação para o desenvolvimento sustentável e a sociabilização de valores humanos na vida contemporânea.

Assim, neste estudo têm-se como objetivo resgatar na história da Educação Ambiental e nos documentos da UNESCO as questões relativas à educação para a sustentabilidade e para a cidadania global, buscando contribuir com os processos da educação formal e não formal.

\section{EDUCAÇÃO AMBIENTAL: UM PERCURSO HISTÓRICO}

De acordo com Lima (2009a) a educação ambiental (EA) no Brasil se constituiu como um campo de conhecimento e de atividade pedagógica e política. Nasceu como um campo plural diferenciado que reunia contribuições de diversas disciplinas científicas, matrizes filosóficas, posições político-pedagógicas, atores e movimentos sociais a partir do período de 1970. Para o autor, mesmo com toda a diversidade que a constitui percebe-se que as tendências dominantes à época deram uma direção para trajetória da EA no Brasil.

A EA se estruturou a partir de demandas sociais para ajudar o ser humano a construir uma visão de mundo na qual fosse capaz de reconhecer a necessidade de minimizar os impactos ambientais gerados, principalmente, pelas ações antrópicas. Dessa forma, percebeu-se que o campo da EA compreendia um universo pedagógico multidimensional que girava em torno das questões socioambientais. A multiplicidade da EA “conduziu naturalmente a novos esforços de diferenciação desse universo de conhecimentos, práticas e posições pedagógicas, epistemológicas e políticas que interpretavam as relações entre educação, sociedade, ambiente natural e construído e sustentabilidade" (LAYRARGUES; LIMA, 2014, p. 27).

Ao tratar a EA no sentido de "campo" os autores resgatam o termo dos estudos de Pierre Bourdieu, o qual o define como "um espaço plural de agentes sociais e de posições conceituais e políticas que disputam as definições das regras de funcionamento, cultura e valores reconhecidos pelos integrantes de um determinado universo social que ele denomina de "campo" (LAYRARGUES; LIMA, 2014, p. 23). 
Nesse entendimento os autores salientam que se faz necessário compreender que há diferentes tendências politico-pedagógicas na EA. Essa diversidade é um dos aspectos que compõe a complexidade do campo EA. E isso, a despeito de representar uma problemática, oferece uma oportunidade de "refinar o olhar", o que permite aos vários atores sociais, a partir das diferentes interpretações, se posicionarem com maior autonomia no espaço social o que resulta na escolha de caminhos pedagógicos, éticos e políticos em busca de melhor atender aos interesses também diferentes.

Assim, Layrargues e Lima (2014), registram que a partir dos anos 1990, a EA se retirava de um perfil inicial conservacionista (biologicista e técnica) e passava a ser reconhecida pela preocupação com a dimensão social do ambiente. E Czapski (2008) apud Lima (2014), identifica o ano de 2003 como o período que começam no Brasil os debates sobre a conceituação na EA, quando a fórmula de Educação Ecológica do físico Frijof Capra aparece como proposta a ser adotada como política pública educativa pelo governo brasileiro.

Acredita-se que esta proposta mesmo não se efetivando trouxe ganhos para o debate, se não dialogou com todas as vertentes e campos da EA com influência naquele momento ao menos ajudou no dialogo e reflexão, despertando sensibilidades para alguns aspectos e questões não pensadas ou relativizadas até então.

É também na década de 1990, mais especificamente a partir da Rio-92, que o discurso do DS assumiu um lugar de destaque nas questões que envolvem o meio ambiente e o desenvolvimento social em sentido amplo. Obviamente, compreende-se, assim como Lima (2009a), que o DS é uma estratégia político-diplomática da Comissão Mundial sobre Meio Ambiente e Desenvolvimento (CMMAD), das Nações Unidas, conhecida pelo seu objetivo de examinar as questões críticas que envolviam a relação entre o meio ambiente e o desenvolvimento e oferecer propostas para orientar as ações e mudanças nesse âmbito.

Pode-se dizer que o relatório Nosso Futuro Comum (1988), previa ser necessário uma renovação em termos de conhecimento, técnica, tecnologias, produtividade e lucratividade para se conseguir um crescimento econômico e avanço social. "A questão ambiental nesse processo aparecia como um desafio novo que ameaçava a reprodução sistêmica, tanto do ponto de vista da oferta de recursos naturais para a expansão econômica quanto da perspectiva dos resíduos da produção e da poluição daí decorrente" (LIMA, 2009a, p. 157).

Questões essas, as quais, pode-se afirmar, se estendem ainda hoje, juntamente com a visão que acompanha a perspectiva de desenvolvimento desenhada desde a Conferência de Estocolmo, em 1972. A partir dessa conferência, a preocupação dos organismos internacionais era de implementar uma gestão do meio ambiente capaz de entender a preservação num projeto desenvolvimentista. Esta era uma forma de contemplar e inserir as questões ambientais no debate público, mesmo que partindo de uma vertente econômica. 
E foi pelas instituições ambientalistas que a preocupação ambiental chegou à educação formal, ainda assim, colheu-se frutos desse benefício em duas perspectivas, primeiro, no aspecto de publicização e sensibilização do tema e a segunda, no fato da aproximação da temática meio ambiente com o sistema educacional. Contudo, essa aproximação ocorreu também, por outros meios que não exclusivamente das políticas educacionais.

Assim, somente em meados da década de 1990 se institucionalizaram algumas políticas de EA no contexto educacional brasileiro. Essas foram se consolidando, sempre permeada de controvérsias e dependente das múltiplas visões, dos diferentes atores sociais a que estão vinculadas e de onde se originavam. Por outro lado, o DS, ao adquirir seu reconhecimento e se constituir em um centro de interesse de atividades emergentes avança para a educação e vai ocupando um espaço que antes era da EA. Ao aproximar-se do processo educacional, o DS chega com algumas terminologias, tais como: educação para o desenvolvimento sustentável, educação para o futuro sustentável, educação para a sustentabilidade.

Essa renovação discursiva em relação à EA ocorreu desde a Conferência Internacional de Tessalônica, realizada na Grécia, em 1997, com o tema "Educação para um Futuro Sustentável”. Nesta oportunidade, já circulava um texto da UNESCO anunciando que estava sendo desenhada na trajetória do desenvolvimento sustentável a intenção de avançar para o processo educacional.

De acordo com Lima (2003), a maioria dos autores que analisam as propostas de educação para a sustentabilidade ou EDS, concordam que essa perspectiva é uma tentativa de superar alguns problemas da EA praticada nas escolas de diversos países. Nesse sentido, acredita-se que a limitação está na necessidade de mudança paradigmática. O modelo cartesiano-mecanicista ainda prevalece, respinga seus vestígios e atinge a vida social em questões que estão a exigir uma nova compreensão (LIMA, 2003; MORAES, 2014).

Para Moraes (2014), a educação acostumada a trabalhar com certezas, verdades e previsibilidades, não sabe o que fazer diante da crise, do caos, da incerteza, da não linearidade. E por isso, enfrenta dificuldades em compreender o indeterminismo e a incerteza como parte da realidade, assim como, compreender que um novo contexto sócio-político-cultural se anuncia e exige um paradigma integrador, holístico e complexo.

Sabe-se que os pontos cruciais de um paradigma residem nos aspectos ontológicos, metodológicos e epistemológicos. O ontológico relaciona-se ao ser e a sua realidade, para uma construção teórica na perspectiva de uma ecologia dos saberes, a realidade é complexa dinâmica e mutável e abarca outras infindáveis características convergentes e divergentes.

A mudança ontológica que caracteriza a constituição do objeto conduziu mutações na perspectiva epistemológica do sujeito, do observador científico e nos processos de ensino-aprendizagem que implica nas relações entre sujeito e objeto, educador e educando, corpo e mente, enfim, um movimento dialético que perpassa as múltiplas dimensões do ser humano. Quanto aos aspectos metodológicos, estes dizem respeito as formas de abordagem das práticas. 
O sistema educacional requer métodos participativos, interativos e reflexivos, pensar como se ensina, aprende e avalia em contextos renovados necessita de novos métodos. Os sistemas produtivos e organizações empresariais, pautam-se em responsabilidades que exigem renovação ética e moral nas formas de trabalho, negócios, relacionamentos e comportamentos individuais e coletivos em bases e métodos que compreendam estratégias sustentáveis.

Considerando esses aspectos paradigmáticos, percebe-se que a EA ainda não atingiu plenamente os resultados esperados, embora o discurso e práticas sejam recorrentes no Brasil mesmo antes da Constituição Federal em 1988, oficializados nesta, na forma como apresenta o capítulo VI sobre o meio ambiente, artigo 225, inciso VI, estabelece a necessidade de "promover a educação ambiental em todos os níveis de ensino e a conscientização pública para a preservação do meio ambiente;" (BRASIL, 1988, p. 131).

Enquanto isso, a complexidade da crise ambiental se amplia a níveis cada vez mais elevados. É difícil para qualquer ser humano compreender que as características do paradigma vencido, com as quais ele foi educado e aprendeu a viver, precisam ser alteradas, pois, seu comportamento e atitude sociocultural denunciam os vícios de práticas arraigadas.

Como entender e se livrar das atitudes e comportamentos ultrapassados? Talvez sejam estes os maiores desafios na esfera pessoal e profissional que se vive nos dias atuais, entender que o mundo e a humanidade passam por momentos de profunda transformação, em que a postura e comportamento esperado das pessoas, requer reflexão que inclua a busca permanente por mais qualidade de vida e sustentabilidade. Isso precisa ocorrer com urgência, para que se consiga garantir a vida de todas as espécies do planeta. "A qualidade de vida não se restringe apenas ao ser humano, mas a toda a comunidade terrestre, já que somos apenas um elo da grande cadeia do Ser, mas um elo portador de consciência, de sensibilidade e de inteligência” (MORAES, 2014, p. 21).

Essas questões exigem que os educadores tenham clareza epistemológica e estejam abertos para o diálogo interdisciplinar. A segurança epistemológica e um amparo metodológico rigoroso irão possibilitar a compreensão necessária das múltiplas facetas que compõem a realidade e o ser humano. Dessa forma, acredita-se [...] "possam ser incentivados diálogos mais competentes entre ciência, cultura e sociedade, [...] entre ser humano e natureza, entre vida e aprendizagem, entre ciência e consciência”. (MORAES, 2014, p. 29)

Contudo, o que se observa é a necessidade de aprender a pensar em outra lógica. Sem colocar na vida ingredientes como sensibilidade, emoção, alegria e sem trazer a vida para o espaço do ensinar e aprender, sem o diálogo aberto, sem a humildade docente e discente será difícil educar para a sustentabilidade. Por isso, oferecer uma educação para a sustentabilidade passa por repensar as práticas do ensinar e aprender. Elaborando-as, em bases inter e transdisciplinares, o que implica, em atitudes de abertura e capacidade de diálogo em múltiplas dimensões. 
Em Layrargues e Lima (2014), aparecem os temas essenciais na perspectiva da EA crítica, em que os conceitos-chave são: cidadania, democracia, participação, emancipação, conflito, justiça ambiental e transformação social.

Logo a ECG e EDS, dialogam com o pensamento complexo ao compreender a necessidade da abordagem de alguns temas essenciais a ser tratado na questão ambiental no plano educacional, tal como a EA crítica sugere. Pois, qualquer resposta para as questões emergentes em relação ao meio ambiente, devem considerar as "relações entre indivíduo e sociedade, sujeito e objeto do conhecimento, saber e poder, natureza e cultura, ética e técnica, entre outras dualidades" (LAYRARGUES; LIMA, 2014, p. 33).

No entanto, a aproximação que se faz entre a concepção de EA crítica, EDS e ECG respectivamente, encontram-se em estudos mais amplos, que avançam as referências as quais se trás para debater neste estudo. Enquanto outras macrotendências e tendências, de outra forma referem-se a magnitude dos desafios e das incertezas que se vive nesta contemporaneidade, também, dizem respeito as formas e métodos de organização das temáticas de estudo, e por fim, levam para que se pense a educação considerando a complexidade e transdisciplinaridade. Esta, é uma visão educativa necessária, tanto para o ensino quanto para a aprendizagem, e somente viáveis, a partir de um novo olhar sobre a realidade.

\section{EDUCAÇÃO PARA A SUSTENTABILIDADE E PARA A CIDADANIA GLOBAL}

A educação é um bem universal, ninguém pode ser privado, é uma forma de desenvolvimento dos povos e sociedades. O enfoque global da UNESCO está fundamentado nos direitos humanos, compactua com uma educação inclusiva, de qualidade que preenche as necessidades básicas de aprendizagem, é um instrumento de enriquecimento na vida dos estudantes.

"É preciso adaptar os programas, a pedagogia e os métodos de ensino aos estudantes [...]" (UNESCO, 2008, p. 6). No âmbito da educação formal é necessário esforços para ampliar vagas e monitorar a qualidade do ensino em todo os níveis. Quanto a educação não formal, da mesma forma, torna-se necessário elaborar e implementar propostas para dar conta de um amplo espectro de necessidades, bem como, constituir espaços, criar vínculos e incentivar diálogos entre educação formal e não formal. Nessa perspectiva aproveitar o espaço informacional midiatizado, conectá-lo a propostas de ensino e aprendizagem e fortalecer a difusão do conhecimento em âmbito geral.

A educação também deve ajudar e facilitar a relação da educação com o mundo do trabalho e da vida. Dessa forma, compreende-se que as estruturas e modalidades educacionais devem ser flexíveis, diversificadas com vistas a apoiar e incentivar as pessoas a buscar informações e construir conhecimentos que levem a hábitos de vida sustentáveis, com base em saberes renovados.

Em 25 de setembro de 2015, a Assembleia Geral da ONU adotou a Agenda 2030 para o desenvolvimento sustentável, esse marco global carrega a intenção de redirecionar a humanidade para o caminho sustentável, um percurso desenvolvido na carona da Conferência das Nações Unidas sobre o 
DS, Rio + 20, no Rio de Janeiro em 2012, um processo que seu deu ao longo de três anos envolvendo uma série de atores sociais em todo o mundo. (UNESCO, 2017).

O propósito dos 17 ODS, é ajudar a criar uma consciência que venha garantir uma vida sustentável, pacífica, próspera e equitativa na Terra, para todos. Esses são desafios globais para a sobrevivência de toda a humanidade, estabelecem e anunciam restrições quanto ao limite dos recursos naturais. Nesse sentido há necessidade dos governantes dos países signatários da Agenda 2030, alinhar suas propostas e esforços e atuar com responsabilidade política, econômica e socioambiental, quanto a estabelecer medidas para implementação da Agenda 2030.

Nesse contexto a EDS apresenta-se como um instrumento fundamental para atingir os ODS, é assim entendida pela Diretora Geral da UNESCO, Irina Bokova, em fala citada na publicação (UNESCO, 2017, p. 7) em que afirma, "Agora mais do que nunca, a educação tem a responsabilidade de se alinhar com os desafios e aspirações do século XXI, e promover os tipos certos de valores e habilidade que irão permitir um crescimento sustentável e inclusivo e uma convivência pacífica"

A EDS quer desenvolver competências que capacitem as pessoas a refletir sobre as próprias ações considerando seus impactos sociais, culturais, econômicos e ambientais presentes e futuros numa visão local e global, as pessoas devem estar instrumentalizadas “[...] para agir em situações complexas de forma sustentável, o que pode leva-los a adotar novas direções; assim como participar em processos sociopolíticos, movendo suas sociedades rumo ao desenvolvimento sustentável”. (UNESCO, 2017, p. 7)

A ECG quer equipar os estudantes de todas as idades com valores, conhecimentos e habilidades que sejam baseados e promovam o respeito aos direitos humanos, à justiça social, à diversidade, à igualdade de gênero e à sustentabilidade ambiental. E também, quer ajudar a capacitar cidadãos globais responsáveis. A ECG oferece as competências e oportunidades de concretizar direitos e obrigações, com objetivo de ajudar a promover um mundo e futuro melhor para todos. (UNESCO, 2013)

Como já abordamos na introdução deste paper a EDS tem evidência nos ODS em objetivo específico sobre educação associado à educação para a cidadania global ECG ${ }^{4}$, também, promovida pela UNESCO numa perspectiva complementar.

A EDS tem como objetivo geral desenvolver as competências de sustentabilidade transversais nos estudantes, dessa forma oferece apoio a todos os esforços dos ODS, a partir da contribuição com a mudança social, econômica e política, bem como pela transformação e consciência que possa reverberar no comportamento das pessoas para o desenvolvimento sustentável. A EDS pode produzir resultados específicos de aprendizagem cognitiva, socioemocional e comportamental que permitem aos indivíduos lidar com os desafios específicos de cada ODS. Portanto, a EDS permite que todos contribuam para o alcance dos ODS no momento que vem instrumentalizá-los com o conhecimento e as competências de que necessitam, para entender o sentido dos ODS e exercitar a cidadania sustentável e solidária.

\footnotetext{
${ }^{4}$ UNESCO. Educação para a cidadania global: tópicos e objetivos de aprendizagem. Brasilia: 2016. Disponível em: https://bit.ly/3jdGs8D
} 
O compromisso da Unesco com a ECG e com a EDS se configura como uma ação voltada para a paz e fundamenta-se na crença de que: "uma vez que as guerras se iniciam nas mentes do homens, é nas mentes dos homens que devem ser construídas as defesas da paz" (UNESCO, 2013, p. 3) ${ }^{5}$

Nesse contexto a educação é um objetivo em si mesmo quanto um meio para atingir todos os ODS, por isso, há um consenso de que os cidadãos precisam desenvolver competências-chave que lhes ajudem a participar de forma responsável e construtiva no mundo atual. Assim, no documento de Educação para os Objetivos do Desenvolvimento Sustentável: objetivos de aprendizagem, define que: "as competências descrevem os atributos específicos de que os indivíduos precisam para se auto-organizarem em vários contextos e situações complexas. Elas incluem elementos cognitivos, afetivos, volitivos e motivacionais; portanto elas são uma interação de conhecimentos, capacidades e habilidades, motivações e disposições afetivas" (UNESCO, 2017, p. 10). Não se pode ensinar as competências, elas precisam ser desenvolvidas pelos próprios estudantes. O que acontece num processo de ação-reflexão-ação, vivenciado na própria experiência.

Esse viés da educação está presente nos ODS, explicitado nos objetivos educacionais da EDS, se encontra e compartilha objetivos com a ECG, é onde percebe-se a necessidade de desenvolver as metas educacionais, objetivos e resultados de aprendizagem.

A UNESCO identificou as dimensões conceituais principais da ECG que a EDS também compartilha, pois, visa desenvolver competências que capacitem as pessoas a refletir sobre as próprias ações. Preocupa-se com os impactos sociais, culturais, econômicos e ambientais atuais e futuros, por isso, os indivíduos devem ser instrumentalizados para agir de forma sustentável em situações complexas.

O quadro abaixo, deixa mais claro a visão da UNESCO e suas perspectiva de educação na ECG e EDS em relação às necessidades de aprendizagem dos indivíduos para auxiliar no processo de mudança em uma compreensão do desenvolvimento sustentável.

Quadro 1 - Relação entre habilidades e dimensões conceituais da ECG e EDS.

\begin{tabular}{|l|l|}
\hline \multicolumn{2}{|c|}{ Dimensões conceituais chave da ECG e da EDS } \\
\hline $\begin{array}{l}\text { Habilidades Cognitivas } \\
\text { (hard skills) }\end{array}$ & $\begin{array}{l}\text { Os alunos adquirem conhecimentos, compreensão e raciocínio crítico sobre questões globais e } \\
\text { sobre a interconectividade/interdependência entre países e entre diferentes populações. }\end{array}$ \\
\hline \multirow{2}{*}{$\begin{array}{l}\text { Habilidades socioemocionais } \\
\text { (soft skills) }\end{array}$} & $\begin{array}{l}\text { Os alunos tem o sentimento de pertencer a uma humanidade comum, ao compartilhar valores e } \\
\text { responsabilidades e possuir direitos. }\end{array}$ \\
\cline { 2 - 2 } $\begin{array}{l}\text { Habilidades comportamentais } \\
\text { Os alunos demonstram empatia, solidariedade e respeito por diferenças e diversidade. }\end{array}$ & $\begin{array}{l}\text { Os alunos agem de forma efetiva e responsável nos contextos local, nacional e global, em prol } \\
\text { de um mundo mais pacífico e sustentável. }\end{array}$ \\
\hline
\end{tabular}
Fonte: UNESCO (2013, p. 3)

\footnotetext{
${ }^{5}$ Enunciado parte da Constituição da Unesco citado no texto da Educação para Cidadania Global: A abordagem da Unesco, 2013, p. 3

${ }^{6}$ Fonte: desenvolvida pela UNESCO com base em contribuições de especialistas em ECG e EDS de todo o mundo e na Consultoria Técnica sobre Educação para a Cidadania Global, realizada em Seul, Coreia do Sul, em 2013, e o primeiro Fórum da Unesco sobre Educação para a Cidadania Global, que ocorreu em Bankok, Tailândia, em 2013.
} 
Encontramos nos documentos referenciados neste paper os aportes teóricos de educação da EDS e da ECG, as quais nos oportunizam a reflexão em torno das ocupações do ensino e aprendizagem, assim como das estratégias pedagógicas que ensejam as competências e habilidades que as propostas anunciam. Pois, cada uma das perspectivas, têm definidas pela UNESCO, um programa específico com os objetivos de aprendizagem, os quais se encontram com os quatro pilares da educação (DELORS, 1999), aprender a conhecer, aprender a fazer, aprender a ser e aprender a conviver. As propostas educacionais se situam, também, na perspectiva de aprendizagem olhando para diversos contextos. A EDS e ECG pretendem desenvolver conhecimentos, habilidades, valores e atitudes que as pessoas necessitam para contribuir com um mundo sustentável, justo e pacífico num sentido amplo e complexo.

\section{METODOLOGIA}

O delineamento metodológico deste estudo apresenta abordagem qualitativa descritiva e caracteriza-se como um estudo de revisão bibliográfica. A pesquisa bibliográfica é desenvolvida a partir de material já elaborado para outros fins, constituindo-se em fontes secundárias, como livros e artigos científicos, teses, etc. (GIL, 2017). Utiliza-se, portanto, de dados ou de categorias teóricas já trabalhadas por outros pesquisadores e devidamente registradas (SEVERINO, 2007). O autor considera que os textos se tornam fontes dos temas a serem pesquisados e o pesquisador trabalha a partir das contribuições de outros autores.

Desse modo, a pesquisa bibliográfica apresenta como vantagens alternativas de pesquisas, dados que estão prontos e não precisa disponibilizar tempo para coleta de dados empíricos (SEVERINO, 2007). No caso deste estudo, isto facilita, pois, as informações necessárias se encontram publicadas em diferentes fontes relacionadas à temática ambiental e desenvolvimento sustentável.

No planejamento e execução deste estudo foram observados os seguintes passo, descritos por Gil (2017): (a) escolha do tema; (b) levantamento bibliográfico preliminar; (c) identificação das fontes: livros de leitura corrente, obras de referência e periódicos científicos impressos e digitais; (d) leitura exploratória das fontes selecionadas; (e) leitura seletiva e analítica com apontamentos; (f) fichamento de obras e dos artigos selecionados; (g) redação do artigo.

\section{DISCUSSÃO DO ESTUDO}

Esta reflexão se orienta no sentido de pensar o valor das visões de mundo e dos paradigmas nos quais se está acostumado agir, e que amparam as ações e hábitos mais cotidianos. Pois, para qualquer pessoa está difícil compreender o caos, a incerteza e a instabilidade a que se está sujeito nesta contemporaneidade e a cada dia vem se tornando mais presentes na realidade social, assim como nos processos mais básicos de vida. 
Para tudo que se faça do processo mais simples ao mais complexo, todos requerem aprendizado e conhecimento constante, ao mesmo tempo, todos somos demandados por novas competências e habilidades diante da emergência e necessidade que o mundo em suas tangenciais transformações nos arremessa.

Grande parte das situações com as quais nos deparamos não são novidades, porém não foram tratadas como deviam em épocas que estavam surgindo, e hoje, se avolumam pedindo por respostas urgentes, exemplo das questões ambientais, com as quais muito se preocupa na atualidade, sofre-se as consequências de um passado recente de falta de cuidado e atenção com a natureza em coisas muito básicas como desperdício e consumo exacerbado.

Ao analisar o histórico ambiental, percebe-se, desperdiçamos um tempo enorme discutindo quem era o dono do discurso mais valioso, quem detinha mais força e poder para bancar tal projeto e desbancar outro, a quem se iria trabalhar e apoiar o que representava uma postura reativa em relação a grupos distintos que discursavam pelo mesmo tema. Perdeu-se um tempo precioso e irrecuperável. Sim, é importante a identificação, observação e análise conjuntural das tendências e macrotendências que buscam assumir e resgatar para si a apropriação de temas tão relevantes como a questão ambiental, e o que se percebe, é que são múltiplos e multidimensionais os interesses que se vinculam a temática ambiental.

O discurso hoje se orienta no sentido da sustentabilidade do desenvolvimento e da necessidade de trata-lo de uma perspectiva multidimensional que articula os aspectos econômicos, políticos, éticos, sociais, culturais e ecológicos, evitando o reducionismo do passado (LIMA, 1997, p. 213).

As sociedades contemporâneas exigem das pessoas, organizações publicas privadas ou estatais um dinamismo no saber fazer que cria a necessidade destas aprenderem de forma contínua, eficiente e eficaz, pois aquilo que era válido em termos de conhecimento para vida há anos recentes, especialmente quando se pensa nas áreas influenciadas pelas tecnologias, muitos dos saberes e práticas estão superados, e é preciso desenvolver outras.

Por essa razão de acordo com Boer (2007), as modernas tecnologias encurtaram distâncias e provocaram um estreitamento dos espaços e tempos social, econômico e político. Algo que facilitou e viabilizou a interação entre as culturas, aproximou os povos e tornou as economias do mundo interdependentes. Dessa forma, as vidas das pessoas estão cada vez mais influenciadas pela rede de relações que cultivam com diferentes grupos.

Com isso pode-se afirmar que o ser humano faz parte de um todo maior, o que aumenta a responsabilidade individual, no sentido de interagir numa perspectiva de cuidado e atenção às questões coletivas, que dizem respeito a toda humanidade. "Na construção de uma visão de mundo contemporânea, é preciso que os elementos de visão de mundo anteriores e seus aspectos de intuição, emoção e imaginação sejam considerados, porque são referências afetivas e culturais das pessoas" (BOER, 2007, p. 64)

O conhecimento e desenvolvimento de competências e capacidades humanas é fundamental, não apenas é importante para as organizações produtivas, mas é importante para a construção da sociedade democrática como um todo, para ajudar a desenvolver pessoas melhores e mais bem 
preparadas do ponto de vista, de construir uma vida com autonomia e dignidade, frutos do trabalho, interação social e integração ambiental, e também, importante para que se aprenda a viver com mais qualidade e satisfação.

Pensar numa EDS e educação para ECG torna-se fundamental neste momento de absoluta crise que se vive. Para entender o homem, o mundo e a sociedade contemporâneos é necessário a abordagem cosmo-bio-antropológica de Morin (2000), as reflexões e teorias sobre a condição humana não dependem apenas do ponto de vista das ciências humanas, das reflexões filosóficas e das descrições literárias, dependem também das ciências naturais, como a cosmologia, as ciências da terra e a ecologia, pois são essas ciências que podem organizar e aproximar o conhecimento disperso e compartimentado, podem ajudar o homem a refletir sobre as questões fundamentais sobre a vida e o mundo.

Pensar uma educação para a sustentabilidade e cidadania global requer uma forma complexa de entender a ordem e a desordem, a ambiência e a ambivalência porque as contradições apresentam-se juntas. Nas palavras de Stochero, Dias e Boer (2019, p. 28), "este é um grande desafio para os envolvidos na construção de um mundo melhor e de um modelo de ensino e de aprendizagem mais interessante, tanto para alunos quanto para professores". Nesse processo, os instrumentos de ensino podem colaborar para que a educação seja inovadora e a aprendizagem, motivadora para todos.

Entende-se que esta busca deverá se caracterizar pela aprendizagem significativa, eficiente, rápida e contínua. Pois todo o sistema que envolve o viver nas dimensões pessoal, profissional e social são um continuo de incertezas, a exigir das pessoas transformações e modificações constantes na forma de ser e perceber a realidade.

Toda as preocupações que se tem com a questão ambiental vem de um modelo de sociedade voltado para a exploração ambiental, produção de bens materiais, consumo exacerbado e acumulação de riqueza, noutra ponta a pobreza, fome e miséria, degradação ambiental e social, são crises que demandam por solução em âmbitos sociais, educacionais, culturais, econômicos, etc. De tantas ordens são os problemas originados, na mesma proporção são as demandas por respostas.

E dessa forma que se chega ao tema educação para o desenvolvimento sustentável, pois, para um mundo com tais características, é necessário que pensemos no enfrentamento desses desafios de forma ampla e amparado em visões de mundo e paradigmas renovados. Não há mais tempo para pensar quem faz o quê? E qual nome se dá ao fazer? Porque, o que realmente importa neste momento é o fazer amparado num processo educacional. Com foco nas pessoas, ajudar para que percebam o quanto de aprendizado e cooperação o momento exige em relação ao cuidado, consigo, com o outro e com meio ambiente.

A Educação para o Desenvolvimento Sustentável (EDS), formal ou não formal propiciada nos mais diversos espaços é hoje uma necessidade premente, e precisa avançar. 


\section{CONSIDERAÇÕES FINAIS}

Vivenciamos um paradoxo, somos adeptos e utilizamos com alegria dos avanços tecnológicos, atraídos pelo consumo e pela proposta de felicidade embutida neles, esquecemo-nos de olhar a crise ambiental efeito de um processo produtivo sem reflexão e nem prospecção de futuro. Esquecemo-nos de olhar o número expressivo de seres humanos que estão excluídos do cenário socioeducacional.

Não há nada de novo nesse cenário, exceto a constatação de as questões e reveses do passado não foram tratados como deviam, isto é, quando apenas emergiam, e hoje, tomam proporções volumosas, pedem por ações urgentes que demandam atitudes e comportamentos renovados de agentes públicos e sociedade civil. Um panorama com sérias implicações socioambientais, com as quais muito se preocupa na atualidade, em que as necessidades de cuidado com o clima e atenção a descarbonização das matrizes energéticas se juntam a uma pobreza educacional. Essas questões sinalizam que os problemas de ordens diversas os quais conduziram a crise em que estamos imersos, são frutos de ações e atitudes de outros, ações tomadas num tempo que impactam a realidade atual negativamente.

Por isso, há um consenso da necessidade de desenvolver competências-chave para ajudar as pessoas a participar de forma responsável e construtiva na sociedade, refletir o campo da educação, estimular novas práticas e fortalecer uma visão de mundo que compreenda um ser humano em harmonia consigo, com os outros, com o planeta e com a capacidade de compreender e atuar na perspectiva do desenvolvimento sustentável, considerando as áreas de importância crucial para a humanidade.

Logo, considerar as pessoas, planeta, prosperidade, paz e parceria, é fator que compreende ações educacionais. Assim, respeito aos valores de pluralismo, solidariedade, compreensão mútua e diversidade cultural, evidenciam os pressupostos que amparam a Agenda 2030 e a EDS e ECG. É uma forma de assegurar que o propósito da nova agenda seja realizado, e são também, desejos comuns de que juntos estaremos caminhando para um futuro melhor para nós próprios e pensando no futuro das próximas gerações.

\section{REFERÊNCIAS}

BRASIL. Constituição da República Federativa do Brasil: promulgada em 5 de outubro de 1988. Disponível em: https://bit.ly/2S5JdgD. Acesso em: 30 mar. 2020.

BOER, N. Educação ambiental e visão de mundo: Uma análise pedagógica e epistemológica. Tese de doutoramento em Educação Científica e Tecnológica na Universidade Federal de Santa Catarina. Florianópolis: 2007. 
COMISSÃO MUNDIAL SOBRE O MEIO AMBIENTE E DESENVOLVIMENTO. CMMAD. NosSo

Futuro Comum. Rio de Janeiro: Fundação Getulio Vargas, 1988.

DELORS, J. Educação: um tesouro a descobrir. 2. ed. São Paulo: Cortez, Brasília, DF: MEC/ UNESCO, 1999.

GIL, A. C. Como elaborar projetos de pesquisa. 6. ed. São Paulo: Atlas, 2017.

MORAES. M. C. Educação e: um olhar complexo e transdisciplinaridade. In: MORAES, M.C.; SUANNO, J. H. (org.). O pensar complexo na educação: sustentabilidade, transdisciplinaridade e criatividade. Rio de Janeiro: Wak, 2014.

LIMA, G. F. C. O Debate da Sustentabilidade na Sociedade Insustentável. Politica e Trabalho. João Pessoa, n. 13, p. 201-222, set. 1997. Disponível em: https://bit.ly/2FZDeaN. Acesso em: 07 jan. 2020.

LIMA, G. F. C. O discurso da sustentabilidade e suas implicações para a educação. Ambiente \& Sociedade. vol. IV, n. 2 jul/dez 2003. Disponível em: https://bit.ly/36b9Skl. Acesso em: 07 jan. 2020.

LIMA, G. F. C. Educação Ambiental Crítica: do socioambientalismo às sociedades sustentáveis. Educação e Pesquisa, São Paulo: v. 35, n. 1, p. 145-163, jan./abr. 2009a.

LIMA, G. F. C. Educação sustentabilidade e democracia: explicitando a diversidade de projetos politico-pedagógico. Desenvolvimento e Meio Ambiente, Curitiba, n. 20, p. 69-75, jul./dez. 2009 b.

LAYRARGUES P. P. ; LIMA, G. F. C. As macrotendências político-pedagógicas da educação ambiental brasileira. Ambiente e Sociedade, São Paulo, v. XVII, n. 1, p. 23-40, jan./mar. 2014.

MORIN, E. Os sete saberes necessários à educação do futuro. São Paulo: Cortez, 2000.

MORIN, E. O método 1: a natureza da natureza. Porto Alegre: Sulina, 2016.

MOSQUERA, J. J. M.; STOBÄUS, C. D. Psicologia positiva e calendário emocional: a construção saudável de si. In: CUNHA, J. L., VICENTINI, P. P. (org.). Corpos, saúde, cuidados de si e aprendizagens ao longo da vida: desafios autobiográficos. Porto Alegre: EDIPUCRS, 2012. 
SAUVÉ, L. Educação ambiental e desenvolvimento sustentável: uma análise complexa. Revista Educação Pública. UFMT, Cuiabá: vol. 6, nº. 10, 72-103, jul-dez, 1997.

SEN. A. A ideia de justiça. São Paulo: Companhia das Letras, 2011.

SEN, A.; KILKSBERG, B. As pessoas em primeiro lugar: a ética do desenvolvimento e os problemas do mundo globalizado. São Paulo: Companhia das Letras, 2010.

STOCHERO, A. D.; DIAS, C. N.; BOER, N. Paradigma da complexidade e a metodologia de projetos: um estudo de revisão teórica. Disciplinarum Scientia, Santa Maria, v.20, n. 1, p. 23 -33, 2019.

SEVERINO, A, J. Metodologia do trabalho científico. 23. ed. rev. e atual. São Paulo: Cortez, 2007.

UNESCO, BRASIL. Setor de Educação. Educação de qualidade, equidade e desenvolvimento sustentável: uma concepção holística inspirada nas quatro conferências mundiais sobre educação organizadas pela UNESCO em 2008-2009. Publicação: nov. 2008. Disponível em: https://bit.ly/2S7I1JG. Acesso em: 01 abr. 2020.

UNESCO, BRASIL. Educação para a cidadania global: a abordagem da UNESCO. Publicado originalmente em 2013. Com título "Global citizenship education: preparing learners for the challenges of the twenty-first century". Disponível em: https://bit.ly/30x6fBJ. Acesso em: 01 abr. 2020.

UNESCO, BRASIL. Repensar a educação: rumo a um bem comum mundial? Brasilia: UNESCO, 2016a. Disponível em: https://bit.ly/3384HQ5. Acesso em: 01 abr. 2020.

UNESCO, BRASIL. Educação para a cidadania global: tópicos e objetivos de aprendizagem. Brasília: UNESCO, 2016b. 73. Disponível em: https://bit.ly/36kSFFf. Acesso em: 01 abr. 2020.

UNESCO, BRASIL. ODS. Educação para os objetivos do desenvolvimento sustentável: objetivo de aprendizagem. Publicado em 2017 pela Organização das Nações Unidas para a Educação, a Ciência e a Cultura, 7, place de Fontenoy, 75352 Paris 07 SP, França, e Representação da UNESCO no Brasil. Disponível em: https://bit.ly/2S97SRq. Acesso em: 01abr. 2020.

RIES, B. E. A aprendizagem sob o enfoque congnitivista: Jean Piaget. In: LA ROSA, J. (Org.) et al. Psicologia e Educação: o significado do aprender. Ed. rev. e ampl. Porto Alegre: EDIPUCRS, 2001. 
